\title{
Jogos, identidade e poder: uma entrevista com Pablo Alabarces
}

\section{Édison Gastaldo}

\section{Resumo}

Paulo Alabarces é um dos mais importantes

intelectuais argentinos e referência na relação entre cultura popular, comunicação e esporte na América Latina. Autor de obras fundamentais como "Fútbol y Patria" (2002) e "Hinchadas" (2005), Paulo examina questões socioculturais das sociedades da América Latina com base em uma mescla de antropologia, estudo culturais e sociologia. Professor Titular no Curso de Comunicação da Universidade de Buenos Aires, Paulo Alabarces tem vínculos com pesquisadores e universidades de toda a América Latina, tendo realizado trabalhos de longo prazo com pesquisadores e instituições brasileiras. Nesta entrevista exclusiva, Paulo fala dos impasses da cultura em sociedades periféricas, hooliganismo, meios de comunicação e cultura dos torcedores, bem como dos próximos megaeventos esportivos no Brasil.

\section{Palavras-chave}

Crítica Cultural; Futebol; Jornalismo; América Latina.

Édison Gastaldo I edisongastaldo@yahoo.com.br Graduação em Publicidade pela Universidade Federal do Rio Grande do Sul (UFRGS), mestrado em Antropologia pela UFRGS, doutorado em Multimeios pela Universidade Estadual de Campinas (Unicamp). Realizou estágio pós-doutoral em Sociologia (Manchester, 2001) e em Antropologia pela Universidade Federal do Rio de Janeiro (UERJ). Professor adjunto no Departamento de Letras e Comunicação da Universidade Federal Rural do Rio de Janeiro (UFRRJ).
Édison Gastaldo: Como a de muitos outros intelectuais latinoamericanos, a sua formação foi ampla, passou por várias áreas, em universidades de diversos países. Poderia comentar um pouco a sua trajetória acadêmica, suas principais influências teóricas e pessoais?

Paulo Alabarces: Minha trajetória é o típico produto de uma época em que não existia pósgraduação, que só começou a institucionalizarse na Argentina na década de 1990; é, ao mesmo tempo, típica da saída da ditadura, porque terminei minha graduação no começo da transição democrática, e isto permitiu que eu conhecesse alguns dos melhores professores no final do meu curso. Então, me formei em Letras e comecei a trabalhar na Universidade democrática muito jovem, em 1985, em um curso de Semiologia que era ministrado pela primeira vez. Ao mesmo tempo, me formava com Eduardo Romano, um dos grandes fundadores dos estudos de cultura popular em uma perspectiva gramsciana e populista. Assim, fui 
me deslocando para os estudos de comunicação e cultura popular, abandonando lentamente a semiótica. A partir de 1988, também trabalhei com Aníbal Ford, outro grande estudioso da comunicação e do popular, e um dos que inventaram a interseção com a antropologia. Em meados dos anos noventa, fiz um mestrado em sociologia da cultura, orientado por Carlos Altamirano e Beatriz Sarlo, outros dois grandes mestres. Já estava trabalhando em minha pesquisa sobre culturas esportivas quando a influência de Sarlo, especialmente, combinou-se com o encontro com Eduardo Archetti, o grande antropólogo argentino que, junto com Roberto Da Matta, inventou esses estudos na América Latina. Estas duas influências foram me levando a abandonar o populismo teórico e a incorporar tanto uma perspectiva crítica sobre os cultural studies quanto uma grande influência antropológica. Meu doutorado foi na Inglaterra, em Brighton, junto com Alan Tomlinson que é, por sua vez, um dos fundadores da sociologia do esporte britânica, em estreito diálogo com os colegas que haviam incorporado a etnografia a esses estudos, como Richard Giulianotti e Gary Armstrong. Ao mesmo tempo, sempre trabalhei em um departamento de comunicação, e até hoje continuo, no curso de Cultura Popular fundado por Eduardo Romano. Sou este nó, essa interseção disciplinar: literatura, semiótica, comunicação, sociologia, antropologia, estudos culturais. E também populismo, marxismo, estudos subalternos e pós-coloniais. Com um enorme peso de Gramsci lido pelos britânicos e pelos latinoamericanos. Como dizia Raymond Williams, estou sempre voltando a Gramsci...

Édison Gastaldo: Um de seus temas preferenciais de pesquisa é a violência entre torcedores de futebol. Eric Dunning certa vez comentou que, na Inglaterra, boa parte da violência dos hooligans estava relacionada com a "profecia autocumprida" (self-fulfilling prophecy) da imprensa sensacionalista britânica, que teria estimulado indiretamente, ao espetacularizar a violência, o surgimento de centenas de novos grupos hooligan em todo o Reino Unido. Como você vê a relação entre o discurso da imprensa e a acusação de violência imputada às torcidas organizadas?

Paulo Alabarces: Creio que a relação é muito mais complexa do que descrição de Dunning: acredito que as interpretações de sua equipe em Leicester nunca tiveram muita sutileza. No caso argentino, a imprensa (todo o jornalismo esportivo) participa de uma linguagem comum, a que chamamos de uma ética do aguante ${ }^{1}$, dentro da qual a violência não só é legítima como até obrigatória. E essa linguagem e essa ética são produtos de três décadas nas quais toda a

Termo êmico usado pelos torcedores argentinos, que, literalmente, significa "capacidade de aguentar", mas que engloba os sentidos de valentia, força física e resistência, qualidades entendidas como fundamentais em situações de confronto com outros torcedores ou com a polícia. 
cultura futebolística argentina foi passando do predomínio do cômico e do farsesco a um predomínio do trágico (mudança que começa na ditadura...). O jornalismo não pode, naquela época, tomar distância do que ele contribuiu para formar com o excesso de dramaticidade e, outro problema agudo, com a contaminação de sua linguagem pela do torcedor. Os jornalistas decidiram que deviam ser iguais aos torcedores, exatamente no momento em que a autopercepção dos torcedores e seu papel no espetáculo esportivo, agora hipermercantilizado e global, tornouse desmesurada. Os torcedores passaram a acreditar que eram a única coisa pura, autêntica, acima de qualquer suspeita; assim, seu papel mudou vertiginosamente. Os jornalistas não souberam ler esse processo, ou se limitaram a acompanhá-lo. Diante dos fatos de violência, então, limitam-se a se refugiarem em um cômodo "eles, os violentos", estigmatizante e absolutamente inútil...

Édison Gastaldo: Em seu livro Fútbol y Patria, você analisa o futebol na sociedade argentina como uma "máquina cultural", empregando o termo de Beatriz Sarlo. No Brasil, como em muitos países da América Latina, o futebol já desempenhou um importante papel na construção de um discurso de identidade nacional. Entretanto, mais recentemente, autores como Ronaldo Helal e Antonio Jorge Soares apontam para uma tendência de enfraquecimento desse vínculo entre futebol e identidade nacional. Como você avalia a relação entre "futebol" e "pátria" atualmente em nossos países?

Paulo Alabarces: Estou revisando meu trabalho de dez anos atrás, mas constatando que minhas hipóteses eram corretas. A Argentina já sofreu esse processo de "enfraquecimento" na década de 1990: quando Maradona saiu de cena, esse vínculo não teve em que se agarrar, tornouse pouco mais do que uma mercadoria dos meios de comunicação. Mas, em Fútbol y Patria, eu havia assinalado que a chave estava na relação entre narrativas nacionais, estado e sociedade civil; que o estado havia sido, no transcurso da história nacional, o grande relator nacionalista (com enorme peso, claro, do estado populista do peronismo). Ali estava parte do sucesso de Maradona: um símbolo claramente peronista que substituía a ausência (ou o afastamento) do narrador estatal durante o neoliberalismo, e a fraqueza da sociedade civil em propor relatos alternativos, fora da mídia, claro. Então, em 2010 coincidem a volta de Maradona como técnico, o surgimento de Messi (um novo herói, porém mudo, sem origem plebeia, sem essa carga populista do Maradona) e também um novo estado, populista e peronista, que torna a se apresentar como narrador nacionalista nos festejos do Bicentenário do primeiro governo nacional argentino no mesmo ano. A conclusão é que o futebol só encarna a identidade nacional como mercadoria midiática; para narrar a nação, está novamente o estado, que o faz melhor 
e de modo mais potente. Esta conclusão não pode ser extrapolada para todo o continente; mas temos uma única regra geral, que é a de que precisamos considerar todos estes fatores ao analisar a relação entre esporte e nação: história, estado, sociedade civil, mídia, herois esportivos, etc.

Édison Gastaldo: Outra de suas especialidades é a cultura popular, marcadamente a música. Considerando as enormes transformações que têm ocorrido no universo da produção musical com a introdução de tecnologias digitais, como você vê este processo e sua ação na cultura popular de países latinoamericanos? Nossa dependência estética, técnica e econômica do mercado fonográfico internacional se alterou?

Paulo Alabarces: Não, essa dependência não se alterou, mas também não mudou a enorme capacidade que têm as culturas musicais locais de produzir desvios e interseções locais. Mesmo com o peso do mercado internacional e sua capacidade infinita de se impor, o peso das músicas locais continua sendo decisivo. Claro, isto merece muito mais desenvolvimento $e$ exemplos. Exige, por exemplo, que levemos em conta os desenvolvimentos teóricos mais recentes sobre as relações entre música e identidade, e a capacidade das músicas populares de gerarem - não de refletirem - complexos fenômenos identitários. Por enquanto, as novas tecnologias jogam mais a favor dos públicos e dos artistas do que dos mercados, porque lhes dão mais autonomia para a produção e para a circulação - sem esquecer o fenômeno enorme da pirataria, crucial em nossas sociedades. Isto não é otimismo banal: deve ser complementado considerando a capacidade que têm os monopólios de impor normas restritivas a seu próprio favor.

Édison Gastaldo: Para concluir, como você vê o processo de preparação do Brasil para a Copa do Mundo de 2014? Não somente os estádios, mas toda a cultura do futebol no Brasil está em processo de transformação com os chamados "padrões FIFA" (cadeiras numeradas, ingressos pela internet, reforma e redução da capacidade dos estádios, etc.). A seu ver, como estas transformações afetarão a cultura cotidiana do futebol no Brasil pósCopa do Mundo?

Paulo Alabarces: Acabo de participar de uma reunião em São Paulo onde isto foi discutido com autoridades federais, que estão convencidas de que conseguem ganhar a queda de braço com a FIFA... Inevitavelmente, a FIFA demonstra a cada passo a sua capacidade oligopólica; e é pequena a margem que os governos democráticos têm para disputar esse espaço. Sem dúvida, a resistência global a esse poder deveria ser mais forte, mas temo que as cumplicidades europeias, em primeiro lugar, e, depois, dos demais países, cooptados pela máquina avassaladora da FIFA, deixa pouco espaço para resistências e muito para cumplicidades ou fracassos. 
A Argentina, por exemplo, é simplesmente um cúmplice institucional desse estado de coisas, e a CONMEBOL em seu conjunto é apenas reprodutora do poder global. Nessa direção, resta pouco espaço para imaginar um futebol democrático, democraticamente organizado e democraticamente desfrutado pelas classes populares. 0 caminho apontado é o de um futebol cada vez mais elitizado, onde o espaço popular se limita aos jogadores (e nem todos) e ao público que assiste pela televisão... se é que antes disso todas as emissões não passam a ser feitas pelos canais a cabo ou satélite. Esse futuro é possivel e não é desejável: Mas não somos muitos os que estamos preocupados. Acabo de ouvir as autoridades federais brasileiras alertando contra isto, e se comprometendo a combatê-lo: só me resta confiar nisto. 


\section{Expediente}

A revista E-Compós é a publicação científica em formato eletrônico da Associação Nacional dos Programas de Pós-Graduação em Comunicação (Compós). Lançada em 2004, tem como principal finalidade difundir a produção acadêmica de pesquisadores da área de Comunicação, inseridos em instituições do Brasil e do exterior.

\section{E-COMPÓS I www.e-compos.org.br I E-ISSN 1808-2599}

Revista da Associação Nacional dos Programas

de Pós-Graduação em Comunicação.

Brasília, v.16, n.3, set./dez. 2013.

A identificação das edições, a partir de 2008

passa a ser volume anual com três números.

\section{CONSELHO EDITORIAL}

Afonso Albuquerque, Universidade Federal Fluminense, Brasil Alberto Carlos Augusto Klein, Universidade Estadual de Londrina, Brasil Alex Fernando Teixeira Primo, Universidade Federal do Rio Grande do Sul, Brasil Ana Carolina Damboriarena Escosteguy, Pontifícia Universidade Católica do Rio Grande do Sul, Brasi

Ana Gruszynski, Universidade Federal do Rio Grande do Sul, Brasil Ana Silvia Lopes Davi Médola, Universidade Estadual Paulista, Brasil André Luiz Martins Lemos, Universidade Federal da Bahia, Brasil Ângela Freire Prysthon, Universidade Federal de Pernambuco, Brasil Antônio Fausto Neto, Universidade do Vale do Rio dos Sinos, Brasil Antonio Carlos Hohlfeldt, Pontifícia Universidade Católica do Rio Grande do Sul, Brasil Antonio Roberto Chiachiri Filho, Faculdade Cásper Líbero, Brasil Arlindo Ribeiro Machado, Universidade de São Paulo, Brasil Arthur Autran Franco de Sá Neto, Universidade Federal de São Carlos, Brasil Benjamim Picado, Universidade Federal Fluminense, Brasi César Geraldo Guimarães, Universidade Federal de Minas Gerais, Brasil Cristiane Freitas Gutfreind, Pontifícia Universidade Católica do Rio Grande do Sul, Brasil Denilson Lopes, Universidade Federal do Rio de Janeiro, Brasi Denize Correa Araujo, Universidade Tuiuti do Paraná, Brasi Edilson Cazeloto, Universidade Paulista , Brasil

Eduardo Peñuela Cañizal, Universidade Paulista, Brasil

Eduardo Vicente, Universidade de São Paulo, Brasi

Eneus Trindade, Universidade de São Paulo, Brasi

Erick Felinto de Oliveira, Universidade do Estado do Rio de Janeiro, Brasi

Florence Dravet, Universidade Católica de Brasília, Brasi

Francisco Eduardo Menezes Martins, Universidade Tuiuti do Paraná, Brasi

Gelson Santana, Universidade Anhembi/Morumbi, Brasi

Gilson Vieira Monteiro, Universidade Federal do Amazonas, Brasil

Gislene da Silva, Universidade Federal de Santa Catarina, Brasil

Guillermo Orozco Gómez, Universidad de Guadalajara

Gustavo Daudt Fischer, Universidade do Vale do Rio dos Sinos, Brasil Hector 0spina, Universidad de Manizales, Colômbia

Herom Vargas, Universidade Municipal de São Caetano do Sul, Brasi leda Tucherman, Universidade Federal do Rio de Janeiro, Brasil

Inês Vitorino, Universidade Federal do Ceará, Brasil

Janice Caiafa, Universidade Federal do Rio de Janeiro, Brasil

Jay David Bolter, Georgia Institute of Technology

Jeder Silveira Janotti Junior, Universidade Federal de Pernambuco, Brasi João Freire Filho, Universidade Federal do Rio de Janeiro, Brasil
John DH Downing, University of Texas at Austin, Estados Unidos

José Afonso da Silva Junior, Universidade Federal de Pernambuco, Brasi José Carlos Rodrigues, Pontifícia Universidade Católica do Rio de Janeiro, Brasil José Luiz Aidar Prado, Pontifícia Universidade Católica de São Paulo, Brasil José Luiz Warren Jardim Gomes Braga, Universidade do Vale do Rio dos Sinos, Brasil Juremir Machado da Silva, Pontifícia Universidade Católica do Rio Grande do Sul, Brasil Laan Mendes Barros, Universidade Metodista de São Paulo, Brasi Lance Strate, Fordham University, USA, Estados Unidos Lorraine Leu, University of Bristol, Grã-Bretanha Lucia Leão, Pontifícia Universidade Católica de São Paulo, Brasil Luciana Panke, Universidade Federal do Paraná, Brasil Luiz Claudio Martino, Universidade de Brasília, Brasi Malena Segura Contrera, Universidade Paulista, Brasil

Márcio de Vasconcellos Serelle, Pontifícia Universidade Católica de Minas Gerais, Brasil Maria Aparecida Baccega, Universidade de São Paulo e Escola Superior de Propaganda e Marketing, Brasi

Maria das Graças Pinto Coelho, Universidade Federal do Rio Grande do Norte, Brasil Maria Immacolata Vassallo de Lopes, Universidade de São Paulo, Brasil Maria Luiza Martins de Mendonça, Universidade Federal de Goiás, Brasil Mauro de Souza Ventura, Universidade Estadual Paulista, Brasil

Mauro Pereira Porto, Tulane University, Estados Unidos

Nilda Aparecida Jacks, Universidade Federal do Rio Grande do Sul, Brasi Paulo Roberto Gibaldi Vaz, Universidade Federal do Rio de Janeiro, Brasi Potiguara Mendes Silveira Jr, Universidade Federal de Juiz de Fora, Brasi Renato Cordeiro Gomes, Pontifícia Universidade Católica do Rio de Janeiro, Brasil Robert K Logan, University of Toronto, Canadá Ronaldo George Helal, Universidade do Estado do Rio de Janeiro, Brasil Rosana de Lima Soares, Universidade de São Paulo, Brasi Rose Melo Rocha, Escola Superior de Propaganda e Marketing, Brasil Rossana Reguillo, Instituto de Estudos Superiores do Ocidente, Mexico Rousiley Celi Moreira Maia, Universidade Federal de Minas Gerais, Brasi Sebastião Carlos de Morais Squirra, Universidade Metodista de São Paulo, Brasil Sebastião Guilherme Albano da Costa, Universidade Federal do Rio Grande do Norte, Brasil

Simone Maria Andrade Pereira de Sá, Universidade Federal Fluminense, Brasi Tiago Quiroga Fausto Neto, Universidade de Brasília, Brasil Suzete Venturelli, Universidade de Brasília, Brasil Valerio Fuenzalida Fernández, Puc-Chile, Chile

Veneza Mayora Ronsini, Universidade Federal de Santa Maria, Brasi Vera Regina Veiga França, Universidade Federal de Minas Gerais, Brasi

COMISSÃO EDITORIAL

Adriana Braga I Pontifícia Universidade Católica do Rio de Janeiro, Brasi CONSULTORES AD HOC

Adriana Amaral, Universidade do Vale do Rio dos Sinos, Brasil Alexandre Rocha da Silva, Universidade Federal do Rio Grande do Sul, Brasi Arthur Ituassu, Pontifícia Universidade Católica do Rio de Janeiro, Brasi Bruno Souza Leal, Universidade Federal de Minas Gerais, Brasil Elizabeth Bastos Duarte, Universidade Federal de Santa Maria, Brasil Francisco Paulo Jamil Marques, Universidade Federal do Ceará, Brasi Maurício Lissovsky, Universidade Federal do Rio de Janeiro, Brasi Suzana Kilpp, Universidade do Vale do Rio dos Sinos, Brasil Vander Casaqui, Escola Superior de Propaganda e Marketing, Brasil

EDIÇÃO DE TEXTO E RESUMOS I Susane Barros SECRETÁRIA EXECUTIVA I Juliana Depiné EDITORAÇÃO ELETRÔNICA I Roka Estúdio TRADUÇÃo I Sieni Campos
COMPÓS I www.compos.org.br

Associação Nacional dos Programas de Pós-Graduação em Comunicação Presidente

Eduardo Morettin

Universidade de São Paulo, Brasil

eduardomorettin@usp.br

Vice-presidente

Inês Vitorino

Universidade Federal do Ceará, Brasil

ines@ufc.br

Secretária-Geral

Gislene da Silva

Universidade Federal de Santa Catarina, Brasi

gislenedasilva@gmail.com 